\title{
Reliability and Sensitivity of Building Performance Simulation Tools in Simulating Mechanically Ventilated Double Skin Façades
}

\author{
Adrienn Gelesz ${ }^{1,2}$, Elena Catto Lucchino ${ }^{3}$, Francesco Goia ${ }^{3}$, András Reith ${ }^{1,2}$, Valentina Serra ${ }^{4}$ \\ ${ }^{1}$ ABUD Ltd., Budapest, Hungary \\ ${ }^{2}$ Budapest University of Technology and Economics, Budapest, Hungary \\ ${ }^{3}$ Norwegian University of Science and Technology, NTNU, Trondheim, Norway \\ ${ }^{4}$ Polytechnic of Turin, Turin, Italy
}

\begin{abstract}
The aim of the paper is to evaluate the performance and reliability of two whole-Building Energy Software (BES) tools in the simulation of narrow-cavity, mechanically ventilated double skin façade (DSF) envelopes. Two popular BES tools (EnergyPlus and IDA ICE) include a dedicated model for the simulation of window systems with a (forced) airflow in the cavity, and can, therefore, be used to simulate mechanically ventilated DSF systems. However, both these simulation approaches are based on the simplified estimation of the thermophysics of the ventilated cavity, and this may lead to inaccuracies in the prediction of the system's behaviour.

Different configurations of mechanically ventilated, narrow-cavity, single-storey high DSFs are modelled with the two BES tools. Their ability to replicate i) the thermophysical behaviour of the systems and ii) the difference in the performance when one parameter in the DSF design is changed (i.e. glazing type and shading on/off) is assessed by means of comparison with experimental data available from test cell experiments. The sensitivity of the tools to (slightly) different configurations is a crucial feature for practitioners, who can use these tools to design DSFs and to take an informed decision on the detailed design of these systems (such as the glazing type and the activation/deactivation of the shading).
\end{abstract}

\section{Introduction}

DSFs can be constructed in many configurations, and BES tools are widely used for assessing building performance with DSFs (e.g. Gelesz and Reith, 2011). The reliability of BES tools is crucial to assure that buildings designed using these tools will perform as planned. The performance of DSFs is usually hard to be assessed through a BES tool, as this simulation environment focuses on the whole building performance simulation, rather than on the sub-components' performance. However, more detailed models for DSFs' simulations (such as those based on CFD techniques) can only focus on the performance of the sub-component, while miss the integration with the entire building (an important feature of DSFs). A trade-off between complexity and usability is therefore necessary, and this has led to the development of dedicated airflow models for windows/façades in BES tools. However, the validation of these models is somehow weak: i) it is often limited to surface temperature values, and not cavity-air temperature, heat-flux values, or transmitted solar irradiance; ii) furthermore, the validation is often carried out on a single configuration, and the sensitivity of these models to different configurations is missing; iii) moreover, inter-software comparison is often not carried out, and this procedure can be useful for understanding the difference between simulation and experiments (Anđelković et al, 2016; Kim and Park, 2011; Mateus et al, 2014). The last major intersoftware validation report (using 5 software tools, including some results for IDA, but excluding EnergyPlus), covering buffer mode and naturally ventilated outdoor air curtain DSFs is almost 10 years old (Kalyanova and Heiselberg, 2009). The results of their empirical and comparative validation showed that for DSFs none of the models appeared to be consistent enough when comparing results of simulations with the experimental data, especially in the periods of higher solar intensity. No evidence can be found in the literature of intersoftware validation of mechanically ventilated DSFs.

This paper thus addresses the validation and cross comparison of two widely used BES tools that include dedicated models for simulating ventilated DSFs (EnergyPlus, IDA ICE). This comparison is carried out on an exhaust-air, narrow-cavity DSF, comparing the results with measured data obtained from experiments in an outdoor exposed test cell.

\section{Façade technology}

Two DSF modules based on the same technologies, differing in the inner side glazing system only, are simulated. The DSFs have a mechanically ventilated cavity of $0.25 \mathrm{~m}$ depth, where the indoor air flows into the cavity from a bottom opening and it is then exhausted through a duct, placed at the top of the ventilated gap. In Figure 1 the two modules are schematically represented,
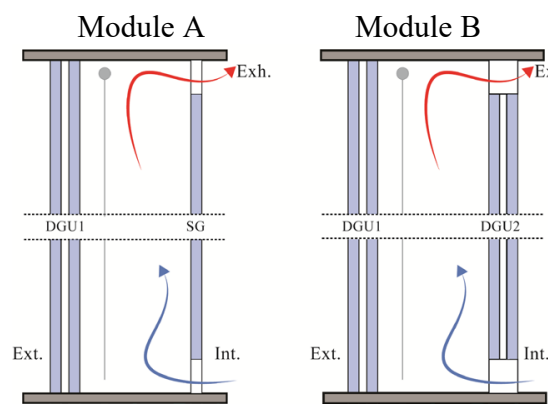

Figure 1: Schematic section of the DSFs. 
the main features of the glazed layers are summarized in Table 2. Modules A and B have the same shading system in the cavity, the same outer-side glazing, airflow rate, and control strategy. Each DSF module is $1.60 \mathrm{~m}$ wide, 3.40 $\mathrm{m}$ high. Both DSFs are ventilated with a flow rate of $20 \mathrm{~m}^{3} / \mathrm{h}$. The shading system is a controllable, highly reflective roller blind placed at $7 \mathrm{~cm}$ from the exterior glazing unit (DGU1).

Four weeks have been chosen for the experimental comparison, including two weeks with shading up (OFF) and two weeks with shading down (ON) (Table 1). These weeks have peak (low/high) temperature and peak solar irradiation representative for the correspondent season. Moreover, each period includes both sunny and warm days, and sunny and cold days, as well as overcast sky conditions.

\section{Methodology - Numerical modelling and simulations}

The measured internal air and surface (walls, floor and ceiling) temperatures of the test cell are used as boundary conditions in the models of the test cell, in order to reduce the inaccuracies related to other test cell parameters that were not characterised (e.g. infiltration rate, emissivity of surfaces), and to assure that the simulated (indoor side) boundary conditions are as close as possible to those experimentally measured.

The weather data file used has been customized for the simulation periods by using the weather data registered in situ. The measurements include recordings of global solar radiation data on the horizontal plane and on the vertical plane of the façade. The required input weather data: global horizontal, direct beam, diffuse horizontal solar radiation, and cloud cover fraction of the sky have been numerically derived for each time step (hourly) from the experimental data available. Wind data was not recorded, thus the effect of the wind speed in the calculation of the outdoor convective heat exchange coefficient is not accounted for. Because of the location of the measurement site and its surroundings, it is possible to assess that the impact of such a simplification is minimal.

The solar optical properties of the glazing and shading have been calculated with LBNL Window 7.6 and Optics6 using the IGDB v29 based on data from technical documentation, while realistic assumptions based on the authors' experience have been made where exact data is
Table 1: Experimental periods.

\begin{tabular}{|c|c|c|c|c|c|}
\hline \multirow{2}{*}{} & \multicolumn{2}{|c|}{} & \multicolumn{2}{c|}{ WINTER } & \multicolumn{2}{c|}{ SUMMER } \\
\cline { 2 - 6 } & Week & $\mathbf{1}$ & $\mathbf{2}$ & $\mathbf{3}$ & $\mathbf{4}$ \\
\hline \multirow{3}{*}{$\begin{array}{c}\text { Outdoor temperature } \\
{\left[{ }^{\circ} \mathrm{C}\right]}\end{array}$} & $\max$ & 7 & 7 & 34 & 26 \\
\cline { 2 - 6 } & min & -1 & -1 & 17 & 12 \\
\cline { 2 - 6 } & average & 3 & 2 & 25 & 18 \\
\hline \multicolumn{2}{|c|}{ Shading device } & ON & OFF & ON & OFF \\
\hline $\begin{array}{c}\text { Max vertical outdoor irradiance } \\
{\left[\mathrm{W} / \mathrm{m}^{2}\right]}\end{array}$ & 866 & 880 & 641 & 797 \\
\hline $\begin{array}{c}\text { Daily horizontal } \\
\text { irradiation }\left[\mathrm{kWh} / \mathrm{m}^{2}\right]\end{array}$ & max & 2.34 & 1.75 & 6.92 & 5.33 \\
\cline { 2 - 6 } & average & 1.67 & 1.3 & 5.5 & 3.79 \\
\hline $\begin{array}{c}\text { Daily vertical } \\
\text { irradiation }\left[\mathrm{kWh} / \mathrm{m}^{2}\right]\end{array}$ & max & 4.98 & 4.47 & 6.7 & 5.44 \\
\cline { 2 - 6 } & average & 2.72 & 2.6 & 3.75 & 3.58 \\
\hline
\end{tabular}

not available (Table 2). Frame properties are set to $10 \%$ frame ratio on both internal and external skin, $\mathrm{U}_{\text {frame, }}$ combined $=1 \mathrm{Wm}^{2} \mathrm{~K}$. Module A and Module B are modelled as two separated elements, not interacting with each other.

The simulation with both tools is run for two consecutive weeks, for each of the four periods, where the first one functions as warm-up period, and the second one is the one used in the assessment (Table 1).

\section{Façades and test cell modelling in EnergyPlus}

The modelling of the DSFs has been carried out with the in-built component "Airflow Window" (as implemented in EnergyPlus 8.8). This component is only meant to simulate forced airflow between glass panes and can run in five different modes, among them the "Air exhaust" mode (U.S. Department of Energy, 2017a). The inlet air is taken from the indoor air node of the thermal zone where the DSF is, and exhausted air is linked to the outdoor air node.

In general, the software allows the modeller to specify the characteristics of a window construction pane by pane, with a limitation of maximum 8 layers in the construction (including glass panes, cavities, shading). Module B presents a number of construction layers that exceeds the maximum allowed by the software. To overcome this limitation, equivalent fictitious glazing systems (interior pane and exterior pane), each made of a single glass pane (instead of double glazing), are created, where the

Table 2: Glazing and shading configurations, solar optical and thermophysical properties.

\begin{tabular}{|c|c|c|c|c|c|c|c|}
\hline ID & \multicolumn{2}{|c|}{ Layers from exterior to interior } & $\mathbf{T}_{\text {sol, out }}$ & $\mathbf{R}_{\text {sol, out }}$ & $\mathbf{R}_{\text {sol, in }}$ & U-value* & g-value* \\
\hline SG & $10 \mathrm{~mm}$ & Laminated clear glass 5.5.4 & 0.7 & 0.066 & 0.066 & 5.59 & 0.788 \\
\hline DGU1 & $\begin{array}{l}20 \mathrm{~mm} \\
16 \mathrm{~mm} \\
10 \mathrm{~mm}\end{array}$ & $\begin{array}{l}\text { Laminated, low-iron glass with selective coating, } \\
\text { pos. } 2,10.10 .4 \\
\text { Air } \\
\text { Low-iron clear glass }\end{array}$ & 0.323 & 0.307 & 0.45 & 1.357 & 0.379 \\
\hline DGU2 & $\begin{array}{l}10 \mathrm{~mm} \\
16 \mathrm{~mm} \\
10 \mathrm{~mm}\end{array}$ & $\begin{array}{l}\text { Low-e clear glass pos. } 2 \\
\text { Air } \\
\text { Laminated clear glass } 5.5 .4 \\
\end{array}$ & 0.515 & 0.225 & 0.146 & 1.507 & 0.64 \\
\hline & & high reflectance roller blind & 0.1 & 0.8 & 0.8 & - & - \\
\hline
\end{tabular}

*At reference conditions defined by ISO 15099:2003. 
fictitious glazing shows the same optical and thermal properties of the original one. The shading device is modelled as "Between glass shade". The position of the shading device is set by default in the middle of the cavity, resulting in two equal cavities with same flow rate. This limitation is connected to the use of the Airflow Window component, which does not allow to specify the exact position of the shading in the cavity.

The other parts of the envelope of the cell are modelled as non-exposed surfaces (nor sun, nor wind exposure). The boundary conditions of the experiment are imposed giving to each surface a temperature as schedule (derived from the available measurements).

The air temperature of the test cell is controlled through the ideal load system, scheduled to reach the set-point equal to the measured indoor air temperature.

The correlations for the external heat transfer coefficient have been set to the "MoWiTT" algorithm (Yazdanian and Klems, 1994), while the other settings have been left on default mode. The MoWiTT algorithm was chosen based on the geometry of the test cell; this correlation is known to be suitable for very smooth vertical surfaces (e.g., windows) in low-rise buildings (Yazdanian and Klems, 1994).

\section{Façades and test cell modelling in IDA ICE}

The Expert edition of IDA ICE 4.8 SP1 is used for this study (EQUA Simulation AB, 2013). The ventilated window model consists of the following elements: two detailed window models representing the two transparent skins; air inlet and outlet components towards the internal, external or the HVAC systems; and a component for the ventilated cavity. The detailed window model makes a layer by layer computation of multiple reflections, and each layer temperature is computed, in accordance with ISO 15099 (International Organisation for Standardisation, 2003). Averaged cavity-air temperatures are calculated based on inlet temperature, mass flow and solar energy and heat transferred through the surfaces.

In case of a DSF, the shading layer needs to be modelled as part of one of the detailed windows, thus only one ventilated cavity is modelled. In the experimental set-up, the cavity-air temperature measurements were done at the inside cavity, hence shading in the model is integrated in the external window model. Cavity depth is given to be equal to the test cell cavity depth, and shading distance is defined as measured from the external skin.

As surface temperatures cannot be directly given as schedules, it was decided to model a guarded ring, i.e. a series of thermal zones around the test cell, where the indoor air temperature schedules are set equal to the corresponding surface temperature measurements. To ensure that the test cell surface temperatures are equal to the guarded ring air temperature, the surfaces dividing the test cell and the guarded ring are modelled as fictitious structures having a very high thermal conductivity (1000 $\mathrm{W} / \mathrm{mK})$, a very small thickness $(0.001 \mathrm{~m})$ and specific heat capacity $(0.001 \mathrm{~J} / \mathrm{kgK})$. The convective heat transfer coefficients of these surfaces are set very high (1000
$\mathrm{W} / \mathrm{m}^{2} \mathrm{~K}$ ) on the guarded ring side, while they are kept on default towards the test cell. Except for the walls incorporating the DSFs, all external surfaces are modelled as adiabatic and disconnected from the building faces. Ideal heaters and coolers are used in all the thermal zones to meet the thermal demand.

\section{Methodology - Experiments and data processing}

As more extensively described in Goia et al. (2014), the two façade modules are mounted on a full-scale office room located in a temperate sub-continental climate location in northern Italy $\left(45^{\circ} \mathrm{N}\right.$ latitude). The orientation of the façade with the modules is $15^{\circ}$ south-west. The indoor air temperature of the room is set at $20^{\circ} \mathrm{C}$ in winter and $26^{\circ} \mathrm{C}$ in summer by means of a combined air system and ceiling radiant panel. The system can operate simultaneously in cooling and heating mode

The modules are equipped with a wide range of sensors: thermocouples and heat flux meter sensors are mounted at three different heights on the façade $(+1,00,+2,00,+3,00$ $\mathrm{m}$ ) in order to account for the temperature stratification. On each module the following parameters are registered: surface temperature of the interior glazing and the exterior glazing (both towards the indoor and the cavity); surface temperature of the roller screen (towards the indoor glazing); cavity-air temperature behind the shading (when present); inlet and outlet cavity-air temperature; frame temperature; heat flux exchanged at the indoor surface of the glazing. The outdoor solar irradiance is measured both on the horizontal and vertical plane by means of two pyranometers. The vertical transmitted solar radiation is measured by other two pyranometers installed on each of the window modules. The measurement accuracies of the sensors are: $\pm 0.3^{\circ} \mathrm{C}, \pm 5 \%$ and $\pm 5 \%$, for thermocouples, heat flux meters and pyranometers, respectively. The indoor environment is also equipped with sensors: on each internal surface a thermocouple measures the surface temperature while the indoor air temperature is measured on three different levels. During the modelling phase, every temperature data and heat flux data collected on three different levels has been area-weighted averaged to obtain one representative temperature value for the entire façade, which is then compared to the single value derived from the simulations.

The comparison between the models and the experimental results is carried out both qualitatively and quantitatively.

The time profiles of the measured and simulated values for the following quantities are compared:

i) surface temperature of the interior surface of the interior glazing,

ii) average air temperature of the cavity,

iii) transmitted solar radiation through the glazing and

iv) heat flux (radiative long-wave and convective) exchanged at the internal surface of the glazing.

In IDA ICE all values can be directly logged as outputs of the software. Conversely, in EnergyPlus, only the quantities i) and iii) are directly obtained as output, while ii) and iv) are obtained through the combination of 


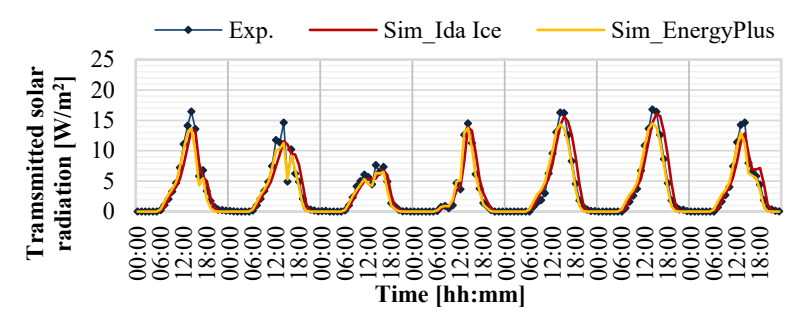

a)

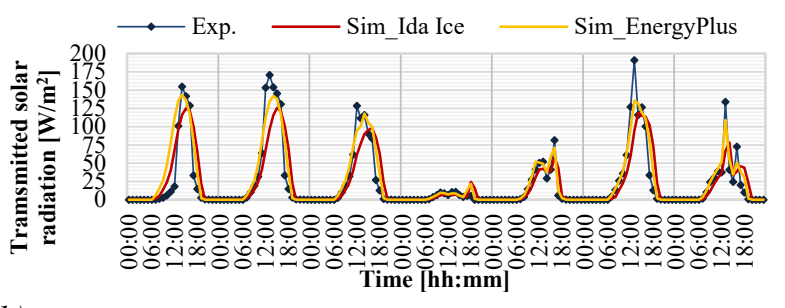

b)

Figure 2: Comparison of the experimental data and simulations for transmitted solar radiation of Module A, a) summer, shading down b) summer, shading up.

different outputs. The average air temperature of the cavity is calculated as the average between the outlet and inlet temperature. This approximation is due to the impossibility of getting as direct output the cavity temperature, which is automatically calculated by the tool based on other variables, which are also not accessible as outputs from the simulation. When the shading is down, the engine determines the surface temperature of the screen, but this value cannot be extracted from the available list of output variables. As for the estimation of the heat flux, the quantities "Surface Window Inside Face Glazing Zone Convective Heat Gain Rate [W]" and "Surface Window Inside Face Glazing Net Infrared Heat Transfer Rate $[W]$ " are summed up and divided by the glazing area (U.S. Department of Energy, 2017b).

Quantitatively, the Root Mean Square Error (RMSE) is used as an indicator of fitness of the models with the experiments, as described in Eq. 1,

$$
R M S E=\sqrt{\frac{1}{n} \sum_{i=1}^{n}\left(X_{\text {sim }}-X_{\text {exp }}\right)^{2}}
$$

where $n$ is the number of measurements, $X$ is the hourly value, the subscript $\operatorname{sim}$ is for the simulated value, exp is for the experimental value. The indicator is calculated for both modules (A and B), for all the four measurements mentioned above (i, ii, iii and iv), and all four periods shown in Table 1.

When assessing the sensitivity of the models to different configurations, the following formula is used for calculating the relative difference of the values of Module $\mathrm{A}$ and $\mathrm{B}$ :

$$
\Delta X_{i}=\frac{X_{\text {Cella }, i}-X_{\text {CellB }, i}}{X_{\text {CellB }, i}}
$$

where $X$ can be any of the physical quantities measured or simulated.

\section{Results}

The time profiles of the measured and simulated values for the selected periods for each physical quantity are compared, and selected graphs are shown on Figure 2-7.

As seen on Figure 2a, the time profiles and the values for the predicted transmitted solar radiation are in good agreement with the experiments for periods with shading down. The peaks are sometime lower for the simulations in periods when the shading is up (Figure 2b).
In Figure 3. the results for the summer period with shading down show that for the indoor surface temperatures IDA ICE has errors in the range from $-1{ }^{\circ} \mathrm{C}$ to $+6{ }^{\circ} \mathrm{C}$ for Module A, but errors are lower in case of Module $\mathrm{B}\left(<2{ }^{\circ} \mathrm{C}\right)$. The minimum and maximum values are closer to the experiments $\left(<2{ }^{\circ} \mathrm{C}\right)$ in EnergyPlus, however, there are some discrepancies in how EnergyPlus models the thermophysical phenomena. The measured internal surface temperatures and heat fluxes present 1-3 hours' delay compared to the simulation results of EnergyPlus, revealing the impossibility of EnergyPlus to replicate inertial phenomena in glazing.

In winter, with shading up (Figure 4), the surface temperatures calculated by both software tools show higher values than the experiments at daytime (errors of IDA ICE $<5^{\circ} \mathrm{C}$, EnergyPlus $\left.<13^{\circ} \mathrm{C}\right)$ and night time $\left(<3^{\circ} \mathrm{C}\right.$ for both tools) as well.

For the cavity-air temperatures it is seen that IDA ICE results are closer to the experiments during winter shading up, but typically much lower in the peaks during summer with shading down. EnergyPlus results are lower than the experimental values in summer with shading down, and higher in winter, with shading up. During the night time results from both simulation tools are higher than the experimental values in the range of maximum $5{ }^{\circ} \mathrm{C}$.

The results for heat flux are the least consistent. Predicted values are closer to the measurements in cases when the shading is down (Figure 5). During this period IDA ICE predicts the heat flux precisely for most of the time with some errors at peaks in the range of maximum $\pm 30 \%$, while EnergyPlus results are higher than the experimental values. In the period of shading up both software tools have errors that are in the order of magnitude of the maximum heat flux value (Figure 6).

\section{Discussion}

To assess the difference in the reliability of the two tools and different configurations, RMSE for each period (Table 3) and the relative cumulative frequency of the errors throughout the total of 4 weeks' simulation (Figure 7) is compared for each quantity and module.

The comparison of the RMSE values shows that IDA ICE predicts the glazing surface temperature, cavity temperature, and heat flux more accurately than EnergyPlus, while for the transmitted solar radiation both software tools give a good estimation, EnergyPlus being slightly more precise than IDA ICE. The errors are typically higher than the sensor accuracies shown above. 


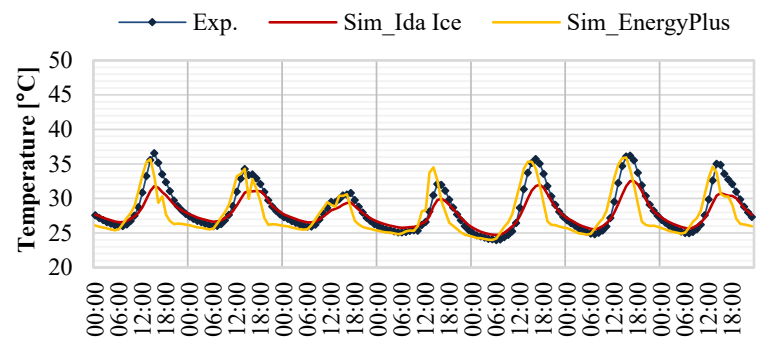

a)

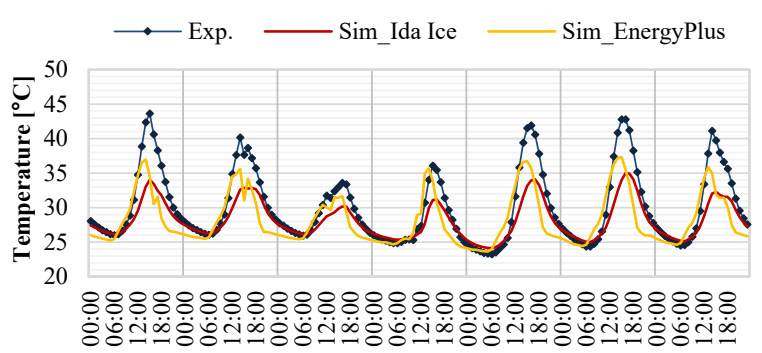

c)

Time [hh:mm]

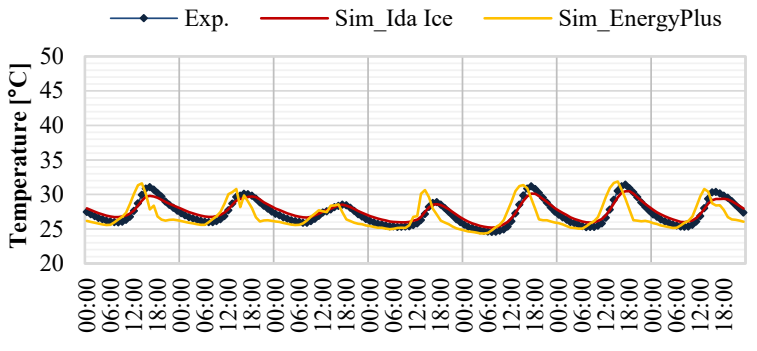

b)

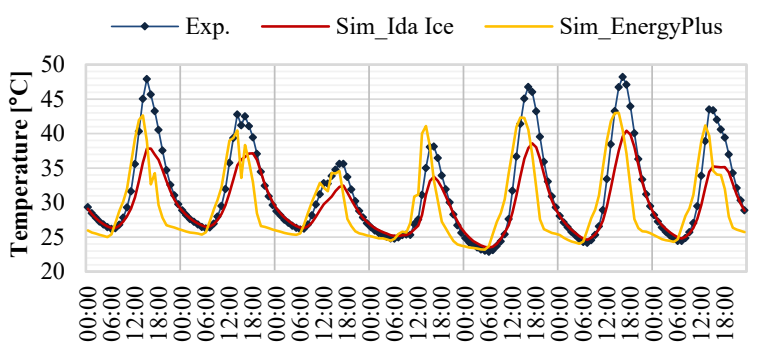

Time [hh:mm]

Figure 3: Comparison of the experimental data and simulations - Summer, shading down. Interior glazing surface temperature: a) Module A, b) Module B; average cavity-air temperature: c) Module A, d) Module B.

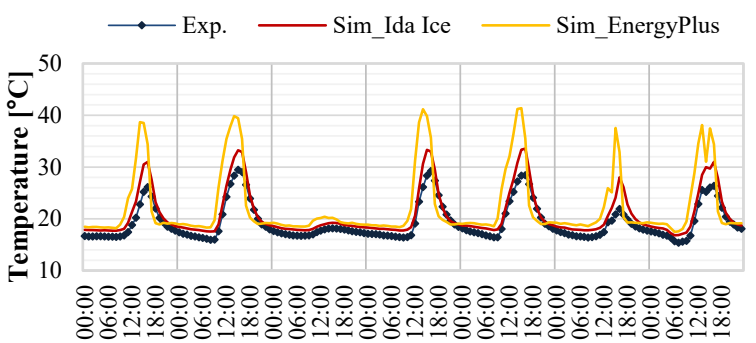

a)

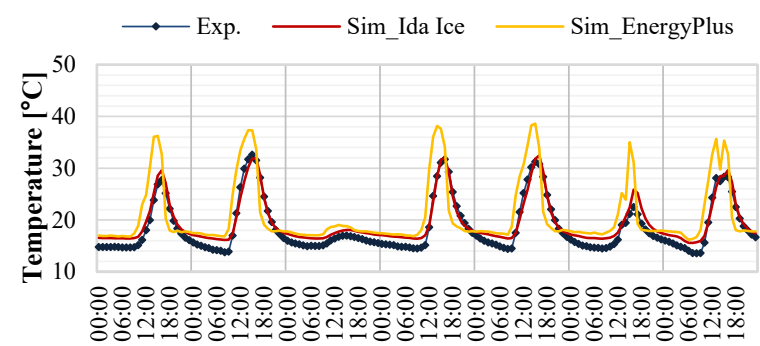

c)

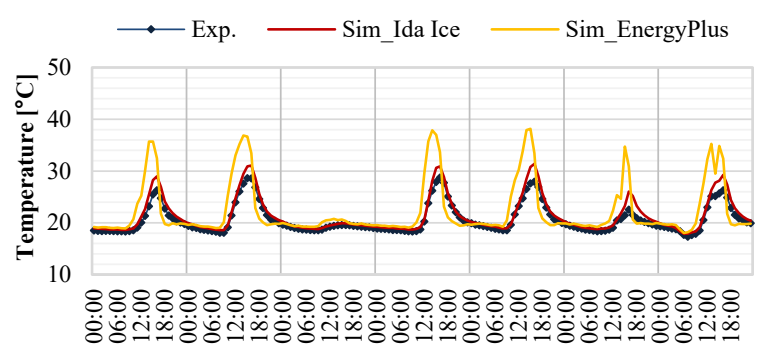

b)

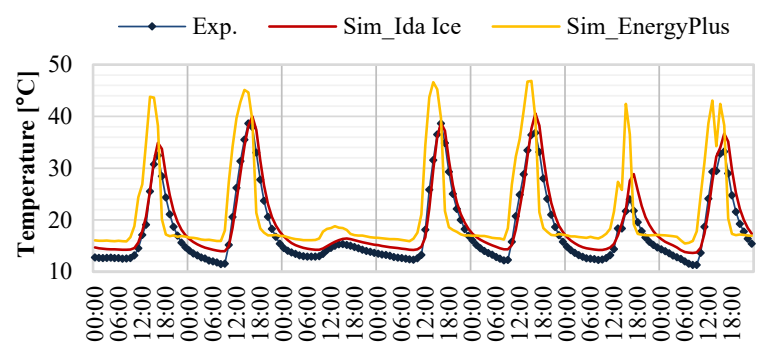

d)

Time [hh:mm]

Figure 4: Comparison of the experimental data and simulations - Winter, shading up. Interior glazing surface temperature: a) Module A, b) Module B; average cavity-air temperature: c) Module A, d) Module B.

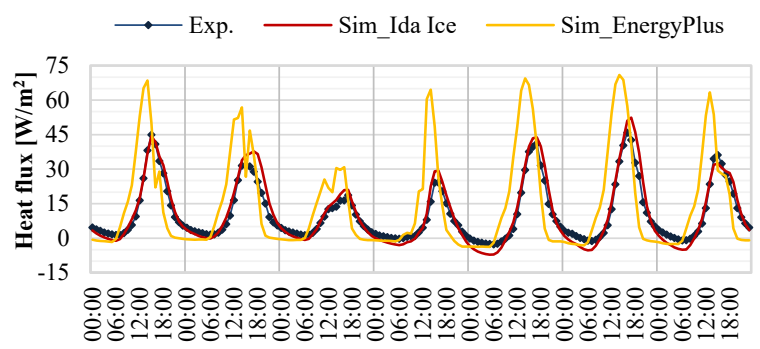

a)

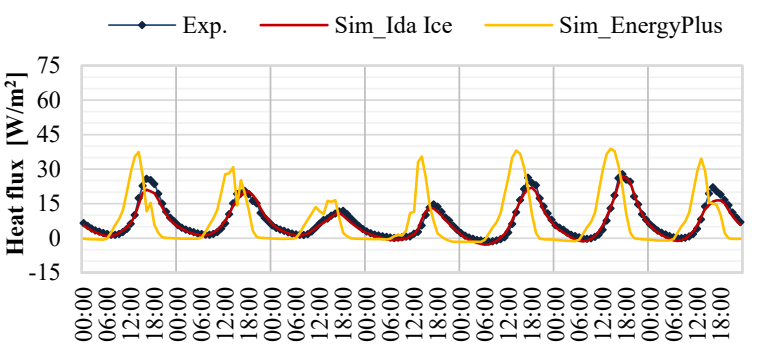

b)

Time [hh:mm]

Figure 5: Comparison of the experimental data and simulations: Summer, shading down. Heat flux (long-wave and convective heat transfer): a) Module A, b) Module B. 
RMSE values tor the internal surface temperatures range from 0.7 to $2{ }^{\circ} \mathrm{C}$ for IDA ICE, while from 1.7 to $5.3{ }^{\circ} \mathrm{C}$ for EnergyPlus. The error for interior glazing surface temperature is within $1.5^{\circ} \mathrm{C}$ for more than $80 \%$ of the time for IDA ICE, but for EnergyPlus this is only true for $3.5^{\circ} \mathrm{C}$ error. This difference in the accuracies is also due to the time shift of EnergyPlus results seen on the time profiles, which is due to the fact that the tool does not take the thermal mass of the glazing into account (U.S. Department of Energy, 2017a). IDA ICE however, does account for this effect, resulting in a much better match between simulated and experimental time profiles.

As far as the cavity-air temperature prediction is concerned, the RMSE values show that IDA ICE is more reliable for periods with shading up, although the two software tools have similar magnitude of errors when the shading in down. The errors are the highest in the summer period with shading down, when both tools underestimate the peak cavity temperatures. Errors in IDA ICE can reach up to $10^{\circ} \mathrm{C}$, while the peaks are more precisely predicted by EnergyPlus, both for the surface temperatures and cavity temperatures. In the winter period with shading up, the cavity temperatures at daytime are captured accurately by IDA ICE, although in the night, values are overestimated. EnergyPlus shows a systematic overestimation for the whole period, but with lower errors than for the surface temperatures.

The deviation of the cavity temperatures can on the one hand be explained by the simplified modelling of the heat transfer from the panes and shading to the cavity-air. On the other hand, this effect might also be due to neglecting the effects of the frames on the cavity-air, as the frames are only modelled as having one dimensional heat flows. In periods of high solar radiation, the frame enclosing the cavity can heat up significantly, while in periods with low external temperatures it cools down. Such an effect is particularly visible on the inlet air temperature because the air flows through the bottom frame before entering the cavity. This causes an initial deviation in the temperature of the inlet air supplied to the cavity, as also seen in a previous study (Saelens et al, 2003).

The transmitted solar radiation is the most accurately predicted quantity among all the assessed variables. The time profiles show good agreement; the RMSE values are

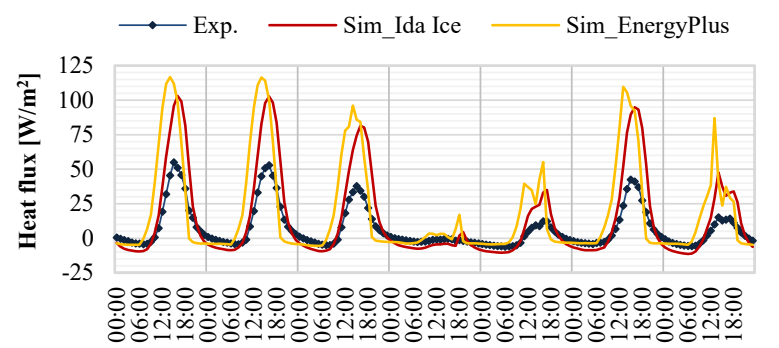

Time [hh:mm]

Figure 6: Comparison of the experimental data and simulations: heat flux of Module A, summer, shading up.

very low for periods with shading down $\left(<3.35 \mathrm{~W} / \mathrm{m}^{2}\right)$, and moderate when shading is up $\left(<27.5 \mathrm{~W} / \mathrm{m}^{2}\right)$. This indicates that the software tools are capable of taking into account the optical properties of transparent structures precisely.

When it comes to the long-wave and convective heat flux exchanged at the indoor surface of the glazing, the errors are typically moderate, with high deviations in the peaks, except for the results of IDA ICE for the periods with shading down, when results are close to the experiments. Apart from the inaccuracy of the models in predicting thermophysical phenomena, another possible cause of the high deviation of heat flux values can be the errors of the measurements when solar radiation is present. In this case, the measurement devices for temperature and heat flux can heat up, which can affect the measured values. Although shielding solutions (Kalyanova et al., 2007) are good practices and have been implemented in the experimental campaign (Goia et al., 2014), these only work with a sufficient accuracy for temperature sensors, as any shielding to avoid overheating due to impinging solar radiation impacts the local thermophysical phenomena around the device. For this reason, the results for heat flux have the largest uncertainty.

Another goal of this research was to evaluate if, and to what extent, the software tools are capable of replicating the difference in performance arising from slightly different configurations.

The effect of the roller blind is properly taken into account when calculating the transmitted solar irradiance, as one can expect, but the effect of the shading on the

Table 3: RMSE for all periods and Modules $A$ and $B$.

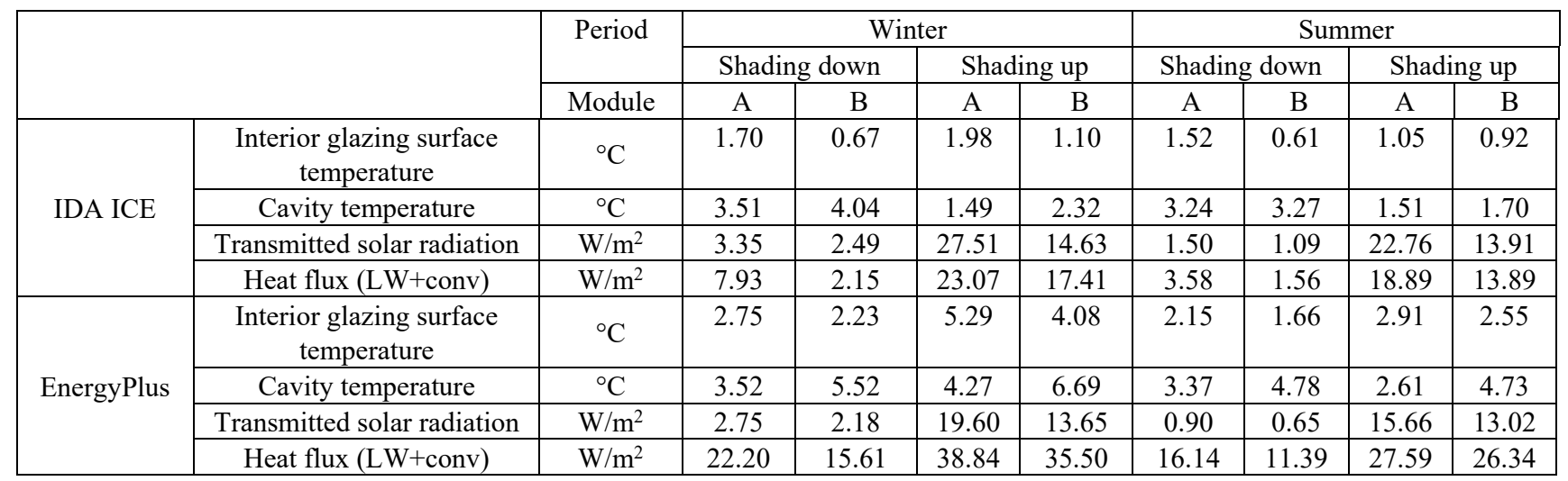



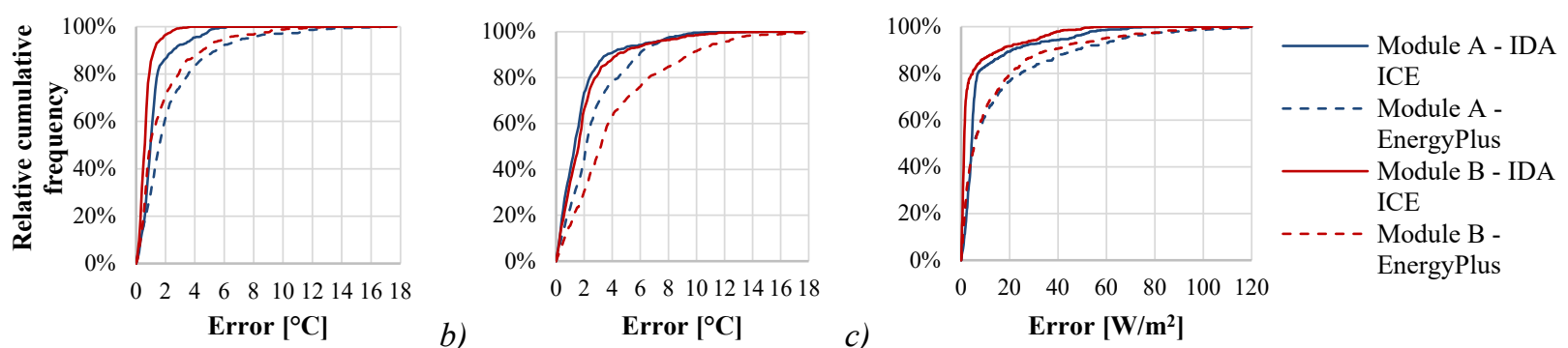

Figure 7: Relative cumulative frequency of the error for the predicted hourly values: a) interior glazing surface temperature, b) cavity temperature, c) transmitted heat flux through the internal glass pane.

temperature rise inside the cavity is underestimated in both software tools. Also, for interior glazing surface temperature and heat flux RMSE values are in most cases lower when shading is down, except for the cavity-air temperature, which is generally predicted with higher errors, although some exceptions exist. This indicates that the calculation of the heat balance of the cavity with shading is not following the real physical phenomena.

The comparison of the results for the single glazed (Module A) and the double glazed (Module B) inside skin shows that the temperature of the interior glazing surface and the heat flux predictions of Module B are more precise, while the cavity-air temperature is more precisely predicted for Module A. The errors of cavity temperature are below $3{ }^{\circ} \mathrm{C}$ for IDA ICE in $80 \%$ of the time for both configurations, while for EnergyPlus there is a big difference in the results of the two configurations.

Although there are errors in the prediction of the values of the cavity-air temperature, the relative difference of the two configurations is in the same magnitude for the experiments and both tools (Figure 8a), with only small deviations for EnergyPlus. However, for internal surface temperatures (Figure 8b), the effect of changing the internal glazing is generally correctly taken into account, but highly underestimated.

When looking at the causes of these discrepancies, it is possible to hypothesize that some physical phenomena are not taken into account in the models; however, some discrepancies could also be due to the intrinsic uncertainties of the experimental setup. For example, the solar transmittance is generally modelled correct and in a detailed way, with $85 \%$ of the values being within an error of $10 \mathrm{~W} / \mathrm{m}^{2}$ for both software tools. The differences seen in peak values might be due to the relative placing of the physical sensors measuring indoor and outdoor irradiance, or to assumptions done to calculate the correct

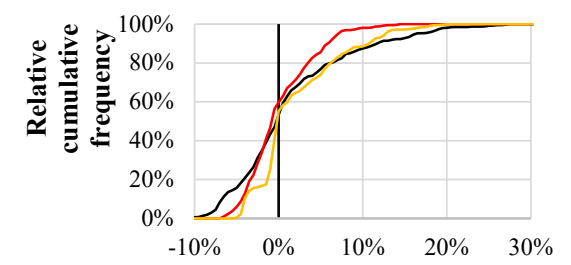

a)

Relative difference weather data variable from measured data. Modelling uncertainties causing errors can be ground reflection or the small deviations due to the lack of the exact glazing or shading optical properties. These uncertainties could be addressed during calibration; however, these are not significant for the overall picture.

Some differences due to aspects that could not be captured in the model are also seen: for example, some peaks in the transmitted solar radiation appear in the simulations that are not present in the experimental data. The models do not take into account any constructions that are perpendicular to the façade plane, while in the test cell the DSFs are constructed between opaque enclosures. At azimuth angles nearly parallel to the façade solar irradiance is still transmitted in the models, although already partially shaded in the reality. (Figure $2 \mathrm{~b}, 4^{\text {th }}$ day) The results of the cavity-air temperature and the internal glazing surface temperature reveal that the heat transfer through the entire system is not simulated with full accuracy. The modelling of the heat transfer coefficients in the cavity are calculated in a simplified way based on temperature or airflow rate only.

The placement of the shading in the cavity also has limited modelling settings in both tools, which cannot take into account the airflow distribution as it is in reality, though it is hard to estimate what could be the impact of such a simplification on the simulation results, as dedicated experiments should be conducted to investigate this aspect.

\section{Conclusions}

The DSF model of two BES tools (EnergyPlus, IDA ICE) was used to compare results of DSF performance to test cell experimental results. While the software tools calculate transmitted solar radiation with high confidence, both tools have notable errors in internal surface temperatures, cavity temperatures, and heat flux.

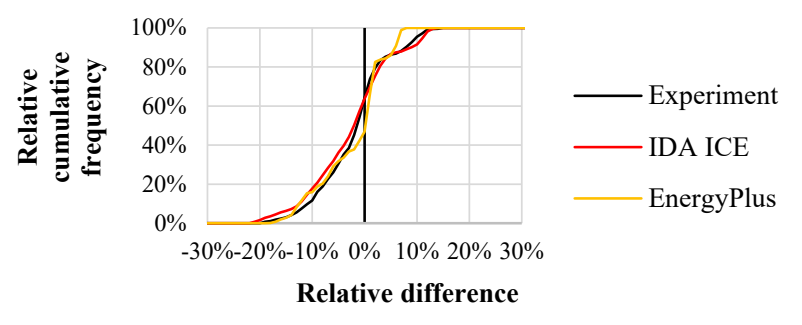

Figure 8: Relative cumulative frequency of the relative difference of temperature values of Module A and Module B, expressed in the percentage of the value for Module B: a) internal surface temperature, b) cavity temperature. 
IDA ICE is more reliable in internal surface temperature prediction; however, the two tools have similar magnitude of errors for the cavity temperatures, underestimating peaks and overestimating temperatures at winter without solar radiation. The model in IDA ICE captures the time profile generally correctly, while EnergyPlus shows a shift in the profiles due to the lack of heat capacity node for the glazing. Such a missing feature is also affecting the values of the heat flux exchanged at the indoor surface of the system by long-wave radiation and convection.

When it comes to the sensitivity of the models to different configurations, the models are generally able to replicate both the direction and the magnitude of change of the cavity-air temperatures for one glazing type and the other. Conversely, the effects of the change on internal surface temperatures are only predicted in a conceptual way, the values of this physical quantity being typically far lower than those recorded by the experiments.

The simulation of the effects of the shading device is correct in terms of transmitted solar radiation, while the impact on the heat balance of the cavity (which is reflected on the cavity-air temperatures and heat fluxes) is not correctly taken into account.

This research shows that it is possible to use a modelling approach based on BES in designing DSFs, but these tools should be carefully used, especially when it comes to the prediction of peak values for sizing of HVAC. In these cases, it might be necessary to add more detailed models to fully replicate the behaviour of these systems, (e.g. effect of inlet and outlet areas, frame properties), as well as adopting other simulation strategies capable of better replicating the complex thermal and fluid-mechanic phenomena in the DSF's cavity.

When comparing to other, custom developed numerical models for DSF performance prediction, e.g. the more detailed model of Zanghirella et al, (2011), it can be seen that the models readily available in the selected BES tools have somehow higher errors. However, their availability is a big advantage for energy modelling professionals trying to evaluate DSF performance during design. These tools can still represent a suitable simulation approach for preliminary screening of alternative solutions, at least as far as the main, overall performance of the system is concerned, and if the thermophysical properties of the air extract from the cavity are not important variables (e.g. if the DSF is to be used as a supply air system, the inaccuracy on the convective gain/loss provided by the ventilation airflow can be too high).

\section{Acknowledgements}

This research paper is a collaborative effort linked to the research activity "REsponsive, INtegrated, VENTilated REINVENT - windows", which is supported by the Research Council of Norway research grant 262198 and by the industrial partners SINTEF and Hydro Extruded Solutions.

Supported by the ÚNKP-18-3 New National Excellence Program of the Ministry of Human Capacities.

\section{References}

Anđelković, A. S., Mujan, I. and Dakić, S. (2016). Experimental validation of a EnergyPlus model: Application of a multi-storey naturally ventilated double skin façade. Energy and Buildings 118, 27-36.

EQUA Simulation AB (2013) EQUA Simulation AB User Manual IDA Indoor Climate and Energy

Gelesz, A. and Reith, A. (2011). Classification and reevaluation of double-skin facades. International Review of Applied Sciences and Engineering 2(2), 129-136.

Goia, F., Bianco, L., Perino, M. and Serra, V. (2014). Energy performance assessment of and advanced integrated façade through experimental data analysis. Energy Procedia 48, 1262-1271.

International Organisation for Standardisation (2003). Thermal performance of windows, doors and shading devices - detailed calculations (ISO 15099)

Kalyanova, O., Zanghirella, F., Heiselberg, P., Perino, M., Jansen, R.L. (2007). Measuring air temperature in glazed ventilated façades in the presence of direct solar irradiation. Proceedings from Roomvent 2007. Helsinki (Finland), 13-15 June 2007.

Kalyanova, O. and Heiselberg, P. (2009). Empirical Validation of Building Simulation Software: Modelling of Double Facades Final Report, Technical Report IEA ECBCS Annex43/SHC Task 34 Validation of Building Energy Simulation Tools.

Kim, D.W. and Park, C.S. (2011). Difficulties and limitations in performance simulation of a double skin façade with EnergyPlus. Energy and Buildings 43(12), 3635-3645.

Mateus, N. M., Pinto, A. and Da Graça, G. C. (2014). Validation of EnergyPlus thermal simulation of a double skin naturally and mechanically ventilated test cell. Energy and Buildings 75, 511-522.

Saelens, D., Roels, S. and Hens, H. (2003). On the influence of the inlet tem perature in multiple skin facade modeling. Proceedings from The $8^{\text {th }}$ International IBPSA Conference. Eindhoven, (Netherlands), 11-14 August 2003.

U.S. Department of Energy (2017a) EnergyPlus 8.8: Engineering Reference.

U.S. Department of Energy (2017b) EnergyPlus 8.8: Input Output Reference.

Yazdanian, M. and Klems, J. H. (1994). Measurement of the Exterior Convective Film Coefficient for Windows in Low-Rise Buildings. ASHRAE Transactions, 100(Part 1), 1087-1102.

Zanghirella, F., Perino, M. and Serra, V. (2011). A numerical model to evaluate the thermal behaviour of active transparent facades. Energy and Buildings 43(5), 1123-1138. 